\title{
MOTIVATING LARGE GROUPS OF LAW STUDENTS TO THINK CRITICALLY AND WRITE LIKE LAWYERS: PART 1
}

\author{
Angela Diane Crocker \\ BSC LLB LLM \\ Lecturer, University of KwaZulu-Natal, \\ Attorney of the High Court of South Africa
}

\begin{abstract}
SUMMARY
This two-part article explores two central themes - student motivation and critical thinking - as they relate to teaching law students how to write like lawyers. The article examines these two themes through the lens of a case study on a legal writing programme, the "Write it Like a Lawyer" [WiLL] programme implemented at the University of KwaZulu-Natal, Durban, in 2019. The design of the programme draws upon three distinct teaching principles - constructive alignment, learner participation and conversations in feedback. This article argues that by applying these principles when teaching legal writing, law students are motivated to engage critically with legal materials, thereby enabling them to produce persuasive, logical, coherent legal writing, containing well-substantiated arguments.

The article is in two parts.

Part 1 begins by focusing on the theoretical underpinnings of the main themes of the article as well as the teaching principles applied in the WiLL programme. It then goes on to describe the significance of the central themes to a legal writing programme such as WiLL.

Part 2 of this article moves on to a discussion of the three teaching principles constructive alignment, learner participation (including blended-learning techniques) and conversations in feedback - and the manner in which these principles were used to achieve the desired outcomes in the WiLL programme. Finally, the second part of the article evaluates the relative success of employing the three principles in order to further student motivation and critical thinking in the programme. The article concludes with recommendations for improvements that could be implemented in future such programmes.
\end{abstract}

\section{INTRODUCTION}

"Behind the scenes of a finished product is a messy process of exploratory writing, conversation, discarded drafts, midnight agony."

Bean Engaging Ideas: The Professor's Guide to Integrating Writing, Critical Thinking, and Active Learning in the Classroom (1996) 4. 
Bean's statement highlights how difficult it is to produce a high-quality, persuasive piece of writing, which is exactly what hundreds of law students are required to attempt every year at the School of Law at the University of KwaZulu-Natal. Over the years, the concept of legal writing, and how to teach this important skill, have been debated by numerous academic writers. ${ }^{2}$ Bridge notes that these writers are not always in agreement on how to approach this concept:

"The existence of 'legal' writing is challenged; its major divisions are disputed; the possibility of teaching it is doubted. Agreement comes only at the point of bemoaning its low level".

It stands to reason that teaching law students how to improve their basic legal writing skills in order to produce high-quality writing is difficult, and this task is not made any easier by the hours of tedious practice and countless drafts required to hone these skills. However, the task is not impossible and with a little imagination, it can be achieved. The key is student motivation. If law students' innate curiosity is piqued and they are motivated to engage on a sufficiently deep level with the learning process, their critical thinking skills can improve, which in turn can open the door to improving their ability to write like lawyers.

The aim of this two-part article is to explore two central themes - student motivation and critical thinking - as they relate to teaching law students how to write like lawyers. The two parts examine these two themes through the lens of a case study of a legal writing programme, the "Write it Like a Lawyer" [WiLL] programme implemented at the University of KwaZulu-Natal, Durban, in 2019. The programme's design draws on three distinct teaching principles - constructive alignment, learner ${ }^{4}$ participation and conversations in feedback. This two-part article argues that by applying these principles when teaching legal writing, law students are motivated to engage critically with legal materials, thereby enabling them to produce persuasive, logical, coherent legal writing ${ }^{5}$ containing well-substantiated arguments. All of these

2 Various models of teaching legal writing exist: Boughey advocates for discipline-specific academic literacies (Boughey "Department-Specific Writing Centres Linked to Tutorial Programmes: The Quest for Quality" 2012 26(1) SAJHE 51-65); Broodryk talks of the benefits of writing-intensive courses across the law curriculum (Broodryk "Writing-Intensive Courses Across the Law Curriculum: Developing Law Students' Critical Thinking and Writing Skills" 2014 35(3) Obiter 453-456); Quinot writes of transformative legal education (Quinot "Transformative Legal Education" 2012129 South African Law Journal 411); and Bean supports the concept of integrating writing, critical thinking and active learning (Bean Engaging (deas). Greenbaum also summarises several authors' descriptions of the term "legal writing" (Greenbaum "Teaching Legal Writing at South African Law Faculties: A Review of the Current Position and Suggestions for the Incorporation of a Model Based on New Theoretical Perspectives" 2004 Stellenbosch Law Review 6).

3 Bridge "Legal Writing After the First Year of Law School" 1978 5(2) Ohio Northern University Law Review 411.

4 Note that the terms "learner" and "student" are used interchangeably throughout this article.

5 See Crocker "Facing the Challenge of Improving the Legal Writing Skills of Educationally Disadvantaged Law Students in a South African Law School" 201821 PER/PELJ DOI http://dx.do i.org/10.17159/1727-3781/2018/v21i0a1368, fn 13, which points out that Greenbaum summarises a number of authors' descriptions of the term "legal writing", all of which emphasise that the legal writer, in addition to displaying competent grammatical 
principles embrace constructivist, learner-centred, blended-learning teaching methodologies and all are intricately linked by a scaffolded teaching-andlearning experience. ${ }^{6}$

As stated above, this article is split into two parts. Part 1 begins by focusing on the theoretical underpinnings of the main themes of the article as well as the teaching principles applied in the WiLL programme. It then goes on to describe a five-week legal writing intervention [WiLL] implemented at the School of Law, University of KwaZulu-Natal (UKZN), Howard College Campus, and the significance of the central themes to a legal writing programme such as WiLL.7

Part 2 of this article moves on to a discussion of the three teaching principles - constructive alignment, learner participation (including blendedlearning techniques) and conversations in feedback - and how these principles were used to achieve the desired outcomes in the WiLL programme. Finally, part 2 evaluates the relative success of employing the three principles in order to further student motivation and critical thinking in the programme. The article concludes with recommendations for improvements that could be implemented in future such programmes.

\section{THEORETICAL UNDERPINNINGS: INTRINSIC MOTIVATION IN TEACHING CRITICAL LEGAL WRITING}

Learning how to write persuasively in legal discourse is challenging for the majority of law students at UKZN, not just because of the prevalence of second-language speakers in the student body, ${ }^{8}$ but since it requires more than just writing clearly in order to communicate. Bean contends:

"[W]riting instruction goes sour whenever writing is conceived primarily as a 'communication skill' rather than as a process and product of critical thought. If writing is merely a communication skill, then we primarily ask of it, 'Is the writing clear?' But if writing is critical thinking, we ask, 'Is the writing interesting? Does it show a mind actively engaged with a problem? Does it bring something new to readers? Does it make an argument?"9

skills, should also demonstrate an awareness of legal discourse and how to communicate within this community (Greenbaum 2004 Stellenbosch Law Review6).

6 Quinot states that there is a need for "a fundamental shift from formalistic legal reasoning to substantive reasoning under a transformative constitution, for a shift towards a constructivist student-centred teaching model and for the recognition of a paradigm shift in knowledge from linear to non-linear, relational or complex." (see Quinot 2012 SALJ 412).

7 The programme formed part of the 2019 Legal Research, Writing and Reasoning $2^{\text {nd }}$-year LLB module (LRWR). Details of the LRWR module will be elaborated on below. However, the focus of this article is on the 5-week legal writing intervention that formed part of the LRWR module.

8 Note that it is not only the second-language students who struggle to assimilate legal writing skills. Most new law students are participating in legal discourse for the first time and, as such, are novice legal writers and will need to learn to apply the particular conventions attached to writing in this foreign discourse. See Crocker 2018 PER/PELJ 3. See also Rideout and Ramsfield "Legal Writing: A Revised View" 1994 Wash L Rev 60, speaking of the unwritten rules of legal discourse.

9 Bean Engaging Ideas 3-4. 
Persuasive legal writing requires learners to think critically - like lawyers do - by considering numerous elements before beginning the drafting process. These include: identifying an argument and then articulating cogent assertions to justify that argument; considering the target audience; maintaining a logical flow throughout the piece; and, challenging the status quo and finding alternatives that can be justified by evidence. Therefore, the ability to think critically is inextricably entwined with the concept of writing like a lawyer and it is imperative that legal educators focus on honing the critical thinking skills of their students. ${ }^{10}$ Bean maintains, "writing is both a process of doing critical thinking and a product communicating the results of critical thinking". ${ }^{11}$ This seems to imply that good-quality legal writing requires the critical, creative use of relevant sources to develop and communicate a logical, persuasive argument. For example, an important aspect of thinking critically is to be able to use authority, not as an end in itself, but as a justification for a particular position. This focus on justification rather than authority helps develop learners' ability to think creatively in any given situation - a particularly important skill in the legal profession. ${ }^{12}$ Quinot develops this idea of justification further by suggesting that in the context of a transformative constitutional democracy in which learners are being trained to practise, they must be encouraged to reflect critically on the underlying normative considerations behind legal authority when justifying any particular argument. This represents:

"a shift from a 'culture of authority' to a 'culture of justification' - that is, an understanding of the validity of a legal position not because of the force behind it (e.g., as contained in a statute or court judgment) but because of the sound normative considerations upon which it is explicitly based - our pedagogy needs to reflect justification and not authority". ${ }^{3}$

The achievement of the twin goals of thinking critically and the effective communication of the results of that critical thinking is based on a number of building blocks. First, students must have an in-depth understanding of the legal materials, since they will otherwise find it difficult to engage with complex legal concepts at a sufficiently critical level. The inability to comprehend and engage at a critical level will inevitably lead to reduced student motivation, rendering many learners incapable of producing legal writing of the required standard. ${ }^{14}$ Secondly, students must be motivated. It

10 It is interesting to note that the specific outcomes attached to the first exit level outcome of the Bachelor of Laws degree required by the South African Qualifications Authority (SAQA) focus strongly on critical thinking attributes, including requirements that: "The learner has acquired the ability to analyse and comment upon the law critically. The learner has acquired knowledge and understanding of, and ability to critically analyse and comment upon current and controversial legal issues ...The learner has developed the ability to explain, critically analyse and comment upon the relationship between law and society." http://regqs.saqa.org.za/viewQualification.php?id= 22993.

11 Bean Engaging Ideas 3.

12 Quinot 2012 SALJ 417.

13 Ibid.

14 This necessity for law students to engage in the learning process at a deep level is reiterated in the SAQA standards for the Bachelor of Laws degree, which recommends that learning and assessment be integrated and that assessments be designed to achieve, inter alia: "An integration of the achievement of exit-level outcomes in a way which demonstrates 
is argued that focusing on improving learner comprehension not only motivates students to engage at a deep level with the information, but also gives them the intellectual space to flex their critical thinking muscles in order to justify their arguments effectively. ${ }^{15}$

The key, therefore, to teaching critical thinking and writing skills lies in student motivation. ${ }^{16}$ Academic engagement, however, implies more than simply being motivated to work hard, listen to instructions or respond effectively to questions posed during class. Newmann, Wehlage and Lamborn explain:

"Engagement involves psychological investment in learning, comprehending, or mastering knowledge, skills, and crafts, not simply a commitment to complete assigned tasks or to acquire symbols of high performance such as grades or social approval. Students may complete academic work and perform well without being engaged in the mastery of a topic, skill, or craft. In fact, a significant body of research indicates that students invest much of their energy in performing rituals, procedures, and routines without developing substantive understanding."17

Inspiring a large, diverse group of students to engage with the difficult, tedious, creative process of legal writing on a deep psychological level can only be achieved if learners are intrinsically motivated to learn. Learners who are intrinsically motivated to learn are driven to participate in the process, not only because they may want to attain a good mark for the module or to impress the lecturer, but simply because they love learning or because they want to understand. ${ }^{18}$ The advantages of intrinsic motivation are well documented and include increasing learners' ability to comprehend more complex materials, enhancing creativity and promoting long-term memory. ${ }^{19}$

a 'deep' approach to learning and shows that the purpose of the qualification as a whole has been achieved." http://regqs.saqa.org.za/viewQualification.php?id=22993.

15 Curtis and Karp make an interesting point that critical reading and critical thinking are inextricably linked: "Critical reading absolutely encompasses the concept of "critical thinking'. These two skills marry the finding of meaning with the evaluating of meaning, and indivisibly work together. Overall, critical skills should not be treated as something to be isolated - such as with specific courses or texts - but rather should be treated as a part of the atmosphere of every classroom by every teacher." (Curtis and Karp "In a Case, in a Book, They Will Not Take a Second Look!' Critical Reading in the Legal Writing Classroom" 200541 Williamette Law Review 293 295, making reference to Carr "How Can We Teach Critical Thinking?" www.risd.k12.nm.us/instruction/criticalthinking.htm.

16 The idea of student motivation is specifically mentioned in the University of KwaZulu-Natal Policy on Assessment, in relation to providing feedback to students, in which it is stipulated that feedback should be "formulated in such a way that the student(s) can see how to improve their learning and are motivated to do so". CO/01/0312/2012 last updated 3/9/2018. https://soe.ukzn.ac.za/mdocs-posts/policy-on-assessment.

17 Newmann, Wehlage and Lamborn The Significance and Sources of Student Engagement in Student Engagement and Achievement in American Secondary Schools (1992) 12.

18 Voke "Motivating Students to Learn" 200228 Student Engagement http://www.ascd.org/publications/newsletters/policypriorities/feb02/num28/MotivatingStudents-to-Learn.aspx. See also Crocker 2018 PER/PELJ 11-12.

19 Voke http://www.ascd.org/publications/newsletters/policypriorities/feb02/num28/MotivatingStudents-to-Learn.aspx. 
So how do we inculcate such intrinsic motivation in our students? Part of the process is for educators to inspire their learners to excellence. ${ }^{20}$ One way of providing this inspiration is to convince learners that lawyerly writing need not be a boring, lifeless exercise. Bridge makes the point that "writing is peculiarly personal; style can be more identifiable than handwriting". ${ }^{21}$ But what about legal writing? Is it possible that writing like a lawyer need not be dull and tedious, but that legal writing can have some soul? This article argues that it is a misconception that legal writing is a one-size-fits-all deal and that individual writing styles must be forsaken in order to produce a clear, concise piece of written work. ${ }^{22}$ In fact, Bridge writes, "If a separate art of legal writing exists, it does not escape the influence of the writer. To the extent any writing becomes disembodied prose, it is unsuccessful communication between the writer and the reader." ${ }^{23}$ In other words, effective legal writing can indeed have a soul. It is up to legal educators to convince their students that there is an art to producing an elegantly drafted, truly persuasive piece of legal writing - one that is clear, concise and unambiguous, without being dry and dull. ${ }^{24}$ Calleros adds to this, stating that infusing a piece of legal writing with an individual writing style can actually enhance the persuasiveness of the piece:

"Clear, concrete, concise legal writing can and should be active, vivid, and engaging. Indeed, you can enhance the persuasive effect of your writing with a telling metaphor, a dramatic phrase, or an engaging description of events that tells a client's story accurately but in a compelling fashion. In short, 'law does have a poetic dimension', and the narrative techniques employed in a novel can play a role in legal advocacy. If you can grab and hold the reader's rapt attention with clear, concise, engaging writing, your memorandum or brief will drive your points home like a home run with the bases loaded." ${ }^{25}$

However, motivating learners to put the time and effort into their writing that is required to elevate basic writing skills to a level of excellence requires a more creative approach to teaching than merely allowing some leeway in personal legal writing styles. Learners need to care about their subject

20 In this respect, Bridge comments: "To attain minimal vocational proficiency is too narrow a goal, if it be a goal at all. If the law remains, or retains pretension of being 'one of the principal' literary professions, then lawyers, law students, and law teachers must acquire and nurture the desire for excellence." (Bridge 1978 Ohio Northern University Law Review 431.)

21 Bridge 1978 Ohio Northern University Law Review 411.

22 Allowing students to reflect their individual writing styles in their legal writing will, of course, raise further questions. Should learners earn marks for creativity or reflecting their individual writing styles? What proportion of the assessment mark should be allocated to this outcome? What are the minimum legal conventions that must still be met?

23 Bridge 1978 Ohio Northern University Law Review 411.

24 In keeping with the idea that excellent legal writing will be infused with soul, Quinot posits that legal educators must take an entirely different approach to legal teaching and must consider that we are teaching within a transformative constitutional democracy. This means that legal writing, in addition to being concise and unambiguous, must embody the social context within which it operates. Quinot states that "matters of morality and policy, even politics, can no longer be excluded from legal analysis. This means that such matters should also enter the law lecture hall ... The door of the law lecture hall can no longer be shut to what is going on outside it." (Quinot 2012 SALJ 415.)

25 Calleros Legal Method and Writing (2014) 5. 
matter and need to have a sense that learning to communicate effectively in writing could make a difference in a real, practical way. A way to stimulate student motivation and to develop in our learners a will to think critically - to breathe some life into the concept of legal writing - is to pique their natural curiosity by offering them interesting, relevant, contextual problems to solve. Bean believes in "the natural, healthy, and motivating pleasure of problems and in the power of well-designed problems to awaken and stimulate the passive and unmotivated student." 26

Thus, it is argued that inspiring students to excellence in legal writing is a two-step process. The first is to motivate learners intrinsically by showing them that legal writing can have soul - that a creative, personal style can enhance persuasiveness, and be used to solve interesting, complex, relevant real-world problems. The second step is to encourage learners to engage at a sufficiently deep level to allow them to think and write critically. It is submitted that ensuring that these curious, enquiring minds remain motivated and critically engaged requires the implementation of three teaching principles: constructive alignment (offering learners module materials that are constructively aligned and contextually relevant); learner participation (using teaching techniques that encourage class participation); and conversations in feedback (individualising the educator-learner contact).

The theoretical underpinning of these three teaching principles is discussed below with the practical application of the principles in the WiLL programme being discussed in detail in part 2 of this article.

\section{THEORETICAL UNDERPINNING OF THREE NECESSARY TEACHING PRINCIPLES}

\section{Constructive alignment}

The first key teaching principle to be considered when designing an effective legal writing programme is constructive alignment. If a module is constructively aligned it will enhance learner comprehension by ensuring that the programme materials, teaching techniques and assessments are all logically linked and presented in order to achieve the module's intended learning outcomes (ILOs). A focus on learner comprehension stimulates intrinsic motivation by giving learners intellectual space to engage deeply and critically with the module materials. Biggs succinctly explains the process of implementing constructive alignment in a module:

"In setting up an aligned system, we specify the desired outcomes of our teaching in terms not only of topic content, but in the level of understanding we want students to achieve. We then set up an environment that maximises the likelihood that students will engage in the activities designed to achieve the intended outcomes. Finally, we choose assessment tasks that will tell us

26 Bean Engaging ldeas 2-3. 
how well individual students have attained these outcomes, in terms of graded levels of acceptability. These levels are the grades we award." 27

When deciding on ILOs for a module it is important to bear in mind that learners must acquire two different kinds of knowledge - both declarative and functioning knowledge. Thus, in addition to knowledge that learners are able to declare or reproduce, whether orally or in writing, they must also acquire knowledge that serves a function. With regard to legal writing, law students must acquire knowledge that will enable them to think and write like lawyers in a transformative South African context or, as Biggs points out:

"Understanding makes you see the world differently, and behave differently towards that part of the world. We want lawyers to make good legal decisions, doctors to make accurate diagnoses, physicists to think and behave like physicists." ${ }^{28}$

Once the ILOs of a module have been defined, relevant teaching activities for the module must be determined and appropriate assessments must be designed, so as to allow learners to assimilate both declarative and functioning knowledge. Biggs emphasises the need for assessment tasks to mirror ILOs and that these must "refer to sought-for qualities of performance, and it is these that need to be stated clearly, so that the students' actual learning outcomes can be judged against those qualities."29

Lastly, educators should not only include constructive alignment in the design of any legal writing programme, but they should also take the time to explain to learners participating in the programme how and why it has been designed in this way. This should happen in the introductory lecture as it will awaken learners to the persuasive benefits of logical linkages - whether these links be in a programme or in a written work. Modelling logical linkages in this manner facilitates the development and understanding of how mindful alignment and analysis work together to deepen comprehension, enhance critical thinking, and inspire intrinsic motivation.

Effective constructive alignment of a legal writing programme enhances student comprehension of the materials associated with the legal writing activities presented in the programme, leading to much-needed intrinsic motivation for learners. Such an approach also ensures that all programme materials and activities (chosen for their contextual relevance) support critical thinking ILOs, which are essential to thinking like a lawyer; such skills are then rendered a focus of the programme rather than an unintended benefit.

27 Biggs "Aligning Teaching for Constructing Learning" The Higher Education Academy https://www.researchgate.net/profile/John Biggs3/publication/255583992 Aligning Teachin g_for_Constructing_Learning/links/5406ffe-70cf2bba34c1e8153.pdf (accessed 2019-07-29).

29 Ibid. 


\section{Learner participation}

The second key teaching principle to be considered when designing an effective legal writing programme is learner participation. This principle is best implemented by employing a constructivist teaching framework. Quinot agrees, maintaining that:

"learning can only occur through construction of knowledge, teaching must involve learners as active participants. The role of the teacher thus changes from that of the sole and authoritative holder of knowledge that must be imprinted on the blank slates of her students to a role of facilitator that must guide students' own efforts at construction". ${ }^{30}$

In addition to using constructivist teaching techniques, the design of class activities should embrace a scaffolded learning experience, which has been described as a "process that enables a child or a novice to solve a problem, carry out a task or achieve a goal which would be beyond his unassisted efforts". ${ }^{31}$ In this respect, Vygotsky's theory of the zone of proximal development, which incorporates the idea of a relative expert in the field giving guided instruction to learners, is central. This theory is defined as:

"the distance between the actual developmental level as determined by independent problem solving and the level of potential development as determined through problem solving under adult guidance or in collaboration with more capable peers". ${ }^{32}$

By actively participating in discussions on the materials in order to contextualise the information, learners are able to construct their own knowledge as well as play an active role in the knowledge acquisition of their peers. In this way, they are able to enhance their own understanding while simultaneously motivating one another to produce high-quality, persuasive pieces of writing, rather than simply writing to complete an assigned task as quickly as possible. Hedegaard links Vygotsky's theory of the zone of proximal development to the idea of contextualising learning, saying that, " $(t) h e$ underlying assumption behind the [Vygotsky] concept is that psychological development and instruction are socially embedded; to understand them one must analyse the surrounding society and its social relations". ${ }^{33}$ Thus, it is essential that active, scaffolded learning opportunities be embedded in any legal writing programme.

30 Quinot 2012 SALJ 420

31 See discussion on the concept of scaffolded teaching in Crocker 2018 PER/PELJ 5, quoting Cheyne and Tarulli "Dialogue, Difference and Voice in the Zone of Proximal Development" in Daniels An Introduction to Vygotsky (2005) 135, quoting Wood, Bruner and Ross "The Role of Tutoring in Problem Solving" 197617 Journal of Child Psychology and Psychiatry 89-100.

32 Vygotsky Mind in Society: The Development of Higher Psychological Processes (1978). See discussion on Vygotsky's definition of the zone of proximal development in Crocker 2018 PER/PELJ 5.

33 See Crocker 2018 PER/PELJ 11 quoting Hedegaard "The Zone of Proximal Development as Basis for Instruction" 227 in Daniels An Introduction to Vygotsky 227. 
In the constructivist teaching environment, however, the teaching and learning process is more complex than the simple transmission of information from educator to learner. Quinot and Greenbaum comment:

"The teaching-learning process is non-linear, that is knowledge does not flow from the teacher to the student in one direction. There is a complex interaction between what the teacher brings to and does in class and what the student brings to and does in class that defines learning." 34

Thus, scaffolded learning requires not only vertical learning between instructor and learner, but also horizontal peer learning between learners themselves. In this respect, Quinot comments:

"[Constructivism] implies that the richness of the knowledge community becomes a key consideration in effective teaching. Since students learn by engaging, not just on a vertical level with the teacher but also critically on a horizontal level with peers, diversity in the learning community becomes a strength, even a prerequisite. As students actively engage with a greater variety of background experiences (that is, with others that bring very different existing knowledge bases to the knowledge community) their own existing knowledge bases are increasingly challenged." 35

It is at this point of constructivist module design that challenges such as a lack of resources that may be present at the institution become apparent. ${ }^{36}$ However, Biggs has a refreshingly positive take on these challenges, saying that these very problems might, in fact, force educators to include inherently constructivist learning activities that encourage deep learning and the acquisition of functioning knowledge. He states:

"In fact, problems of resourcing conventional on-campus teaching, and the changing nature of $\mathrm{HE}$, are coming to be blessings in disguise, forcing learning to take place outside the class, with interactive group work, peer teaching, independent learning and work-based learning, all of which are a rich source of relevant learning activities." ${ }^{37}$

In addition to providing intrinsic motivation to engage deeply with learning materials, active class participation creates opportunities for learners to think critically. Referencing Kurfiss, ${ }^{38}$ Bean posits that when planning a module with a focus on critical thinking, learners should be presented with "'problems, questions, and issues' that make a course 'assignment centred, rather than text or lecture centered' and holds students responsible for 'formulating and justifying' their sources orally or in writing". He also emphasises the importance of writing assignments "because they are perhaps the most flexible and most intensive way to integrate critical thinking

34 Quinot and Greenbaum "The Contours of a Pedagogy of Law in South Africa" 2015 Stell LR 136.

35 Quinot 2012 The South African Law Journal 421.

36 It is an unfortunate reality that these kinds of challenges have been ongoing at the UKZN School of Law. For a discussion on the challenges encountered as far back as 2009 when implementing the first legal writing programme at UKZN, see Crocker 2018 PER/PELJ 2123.

37 Biggs https://www.researchgate.net/profile/John_Biggs3/publication/255583992_Aligning_ Teaching_for_Constructing_Learning/links/5406ffe70cf2bba34c1e8153.pdf.

38 Kurfiss Critical Thinking: Theory, Research, Practice, and Possibilities (1988). 
tasks into a course and because the writing process itself entails complex critical thinking", in addition to "class discussions, small group activities, and other teaching strategies that encourage students to work collaboratively to expand, develop, and deepen their thinking". ${ }^{39}$

At this point, it must be noted that class participation can be enhanced by using a blend of constructivist teaching techniques and e-learning opportunities. It is imperative to consider participation in the wider blendedlearning community and the impact that e-learning and digital information transmission has on teaching and learning. The Internet has revolutionised the way in which information can be accessed and manipulated, changing the very nature of teaching and learning. With more and more learners having access to digital information, be it on computer or smartphone, research and information gathering has become infinitely more dynamic and educators need to swim with these digital tides of change.

Quinot and Greenbaum maintain that the change in the way information is accessed, manipulated and assimilated via digital formats requires educators to incorporate blended-learning methodologies into their teaching repertoire so as to remain current with changing technology:

"It seems evident that different (or at least varied) skills are required to navigate this new knowledge world. Given the mode and ease of access to information, there is arguably less need for memorising large portions of detailed information and more need for skills in finding and filtering information. The more fluid nature of the knowledge paradigm calls for a move away from a linear step-by-step approach to learning, to a more relational or networked approach." ${ }^{40}$

In addition to this, multimedia tools can significantly enhance the motivational aspect of contextualising the subject matter - for example, by showing inter alia video clips of roleplays, news reports, and debates to illustrate real-world challenges. Quinot and Greenbaum advocate:

"[Information and communications technology (ICT)] thus makes it possible for law teachers to incorporate carefully designed real-world contexts into the learning process in a manner which is very difficult (if not impossible) to achieve in any other way. ICT can thus help the law teacher to bring the realworld context to the class without the logistical challenges of taking the class to the real-world context." 41

Thus, boosting learner participation by using scaffolded learning techniques that take advantage of horizontal as well as vertical learning opportunities in a blended-learning environment, will increase learners' intrinsic motivation as well as improve their critical thinking skills. This has a direct impact on the achievability of the ILOs on critical thinking skills, as learners are motivated to grapple with critical thinking, which is inherent to thinking like a lawyer.

\footnotetext{
Bean Engaging Ideas 5.

Quinot and Greenbaum 2015 Stell LR 37.

41 Quinot and Greenbaum 2015 Stell LR 54.
} 


\section{Conversations in feedback}

The third and final key teaching principle to be considered when designing an effective legal writing programme is that of having conversations in feedback. Learners need to be guided through the process of how to write critically like lawyers through a series of conversations held with an expert in the field. Laurillard posits that, in order for effective teaching and learning to take place, it should occur within a "conversational framework" - that is, "a dialogue must take place somewhere, even if it is only in the learner's mind". ${ }^{42}$ This idea is taken further by Flower who recommends implementing a "framework for enquiry" when engaging in the learning process. This system of enquiry, she maintains, should go further than a simple dialogue and should take the more complex form of a negotiation as well as encourage interpretation of the knowledge being acquired. ${ }^{43}$

Gamoran and Nystrand link this idea of holding a conversation in learning to increased student engagement:

"When students' ideas are taken seriously, this tells the students that they are important members of a learning community, and the work of responding to teachers' questions is more authentic because the students can actually influence the course of the conversation. In this sense, questions that take students seriously promote engagement." 44

These conversations in feedback are a key element to improving student motivation and critical thinking. It is argued that actively engaging learners in conversations in formative feedback during the assessment process and requiring them to justify the critical thinking behind their arguments helps

42 Laurillard Rethinking University Teaching: A Framework for the Effective Use of Educational Technology (1993) 105. See general discussion on Laurillard's "conversational framework" in Crocker The Practical Considerations of Implementing Online Learning Technology at the Howard College School of Law, University of Natal, Durban, Using the Legal Method Module [DLA2LGM] as a Case Study, in Order to Develop an Appropriate Strategy for Its Implementation (master's thesis, University of Natal, Durban) 2003 29-30.

43 See general discussion on Flower's "framework for enquiry" in Crocker The Practical Considerations of Implementing Online Learning Technology 30-31; Maharg and Paliwala "Negotiating the Learning Process With Electronic Resources" in Burridge, Hinett, Paliwala and Varnava (eds) Effective Learning and Teaching in Law (2002) 90.

44 Gamoran and Nystrand Taking Students Seriously in Student Engagement and Achievement in American Secondary Schools (1992) 40-41. Kearney and Beazley support this point by referring to Socratic teaching techniques, which they describe: "In the traditional law classroom, teachers who use Socratic method ask questions designed to challenge their students' assertions and assumptions about cases, laws, and principles. In figuring out the answers to these questions, the students achieve a better understanding of both the legal issues being discussed and the process of legal analysis." Just as Socratic methods are used to get students thinking critically like lawyers, Kearney and Beazley maintain that these techniques should also be used to get students writing critically like lawyers. They posit, "Good writing results from good thinking. It makes sense, then, that tools used to teach good thinking should be combined with tools used to teach good writing when law students are learning how to conduct written legal analysis." (Kearney and Beazley "Teaching Students How to 'Think Like Lawyers': Integrating Socratic Method With the Writing Process" 199164 Temple Law Review 885-887.) 
them become invested in their writing. 45 This further stimulates intrinsic motivation to elevate their standard of writing and to think more critically about what they want to say. It also serves the important purpose of ensuring that learners get exposure to what feedback means and how it can be used.

It is also important that these feedback conversations form part of a process. Writing in any form, but particularly legal writing, can be an intensely personal and sometimes overwhelming process; it is often slow and frustrating in the refinement stages - exacerbated by the amount of time and effort that needs to be invested into each persuasive word. Thus, Bean maintains that the progression of legal writing from first draft to final draft is a process that students should be forced to follow. In this way, learners are discouraged from neglecting to revise a first draft, and then attempting to submit an unrevised version as a final draft. ${ }^{46}$ Greenbaum also promotes the value of this process in writing and suggests using repetition in feedback throughout each stage of the process in order to motivate learners:

"Students should receive feedback on their writing during the various stages in the composing process, and revising takes on a new significance as students develop their own valid professional and personal voices." 47

Novice writers therefore need to be guided carefully through the writing process by a series of conversations with a relative expert in the field providing feedback on each of their attempts. Bridge makes the point that this guidance or supervision is an essential element in the writing experience:

"In legal drafting, in seminars, in law review work, or in moot court work, a key element is supervision. Students must have expert support accessible to them. Readers who will review a written product, criticize its organization, content, and underlying assumptions, and suggest improvements are crucial to the benefit derivable from the experience." 4

These conversations in feedback can be provided in a number of different settings, each time adding to the process valuable intrinsic motivation and the opportunity to think critically. Examples include: delayed feedback given orally by a module lecturer in a large group setting some days after evaluating class work; instantaneous feedback given orally by a module lecturer in more intimate, small-group settings as learners work on a task; peer feedback given orally in small-group settings; delayed, written feedback given by a module lecturer on formal module assessments; instantaneous

45 Specific mention is made of the importance of providing ongoing formative feedback to students in the SAQA standards for the Bachelor of Laws degree wherein it is stated: "Learning and assessment should be integrated. Ongoing formative assessment is required so that learners are given feedback on their progress in the achievement of specific learning outcomes." http://regqs.saqa.org.za/viewQualification.php?id=22993.

46 Bean Engaging ldeas 8.

47 Greenbaum 2004 Stellenbosch Law Review 14.

48 Bridge 1978 Ohio Northern University Law Review 424. 
oral feedback given in one-on-one consultations with a module lecturer; and feedback given by peers. ${ }^{49}$

The two central themes of student intrinsic motivation and critical thinking, as well as the three key teaching principles discussed above, were applied when designing the WiLL programme. The practical application of the teaching principles that were used to encourage student motivation, leading to a deep, critical engagement with the programme content, are discussed in the second part of this article. Below are details of the structure of the WiLL programme.

\section{THE 2019 LEGAL RESEARCH WRITING AND REASONING MODULE AND THE WILL PROGRAMME}

The LRWR module is an 8-credit, semesterised, second-year LLB module with an enrolment of over 300 learners per semester. Learners must each attend one double-period contact session per week. Over the past few years, in order to reduce the class size to approximately 150 learners per contact session, the class was split in half and the lecture was repeated to each group every week. The module content covered theory and practical exercises in critical thinking and legal writing skills, with some practical application. In 2019, however, the LRWR module was reimagined using a transformative, constructivist teaching pedagogical framework. The first part of the module kept a similar structure, with the class being split in two and lectures repeated once each week. These large-group lectures covered content on the theory of critical thinking and formed an essential part of the module, providing a theoretical underpinning for the materials and activities that were to follow. The latter part of the module introduced the WiLL programme, which took on a small-group, participatory, skills-based lecture format. This programme was designed, implemented and administered by a School of Law lecturer in consultation with an applied linguist working in the School of Law; it introduced an active learning ethos so as to encourage the students to put in the practical, hard work that such a module requires. ${ }^{50}$

The structure of WiLL introduced a further reduction in class sizes with the class being split into six groups of 50 students each. Learners were required to attend one weekly double-period contact session. Every week, learners had to complete lecture preparation tasks to enable them to participate in group-work activities during lectures. Assessment of the WiLL programme (comprising two written assignments worth 20 per cent each) formed 40 per cent of the assessment for the entire LRWR module. The first assignment

49 Bridge notes that student-controlled feedback can be just as helpful as that given by faculty: "The law review experience demonstrates that supervision need not be faculty supervision, as long as the critical reading is intelligent, careful and demanding." (Bridge 1978 Ohio Northern University Law Review 424.)

50 Note that some of the positive features of previous writing interventions implemented at the UKZN Law School were incorporated into the programme. See Crocker 2018 PER/PELJ 19-20. 
required learners to draft a case summary and the second assignment required them to compose an article for a legal newspaper column.

The materials, formal lecture preparation, lecture tasks and assessments were all carefully chosen and constructively aligned so as to be congruent with a constructivist teaching paradigm and blended-learning practices.

\section{CONCLUSION}

This article as a whole identifies two themes that are central to the teaching of legal writing to law students: student motivation and critical thinking. An examination of these themes through the lens of the legal writing programme case study, WiLL, reveals three teaching principles that were applied when developing the programme and that are closely linked to the central themes. These principles are constructive alignment, participation and conversations in feedback. All three principles, in addition to being closely linked to the themes of the programme are intricately intertwined, both with respect to their links within educational theory and in their practical application; thus, all must receive equal attention within the programme. This requires a commitment to student-centred, critical teaching using constructivist teaching methods.

Part 1 of this article began by giving an overview of the theoretical underpinnings of the two central themes, discussing, in particular, the way in which they relate to teaching law students how to write like lawyers. Here the importance of intrinsically motivating learners to engage deeply with the concept of critical legal writing - as well as with the programme materials used to facilitate the acquisition of this skill - was considered. It is argued that educators running an effective legal writing programme must encourage learners to want to learn and to want to be excellent at legal writing. In other words, learners must be intrinsically motivated to learn how to write like lawyers. This is not an easy task, but intrinsic motivation can be inspired in various ways, such as by revealing that legal writing can have soul - the idea that legal writing need not be dull but instead can have a personal style that assists in enhancing its persuasiveness. Learners can also be enticed into engaging more deeply with the writing that they embark upon by having their interest piqued with contextualised, relevant, interesting problems that they can solve in order to make a difference. An important part of this process is to ensure that learners comprehend the materials at a deep, critical level. This allows them the space to engage and think deeply about how to solve the problems with which they are presented using their legal writing skills. In other words, learners must be given every opportunity to excel.

The focus in part 1 of this article then shifted to a discussion of the theoretical underpinning of the three key teaching principles that were employed when designing the WiLL programme. It was shown that each of these principles furthers student intrinsic motivation and maximises the opportunities for learners to engage in critical thought and critical legal writing.

Finally, part 1 of this article gave a detailed description of the ethos and background leading to the development of the WiLL programme, which was 
designed with the three key teaching principles in mind, in the context of the central themes and learning how to write like a lawyer.

Part 2 of this article explores the practical application of the four teaching principles identified as essential when implementing the WiLL programme. It scrutinises the importance of the constructive alignment of the module and the careful selection of module materials and classroom activities within a constructivist, learning environment focusing on participation and conversations in feedback. Thereafter, part 2 identifies challenges experienced and suggests recommendations for improvement. Final conclusions are then drawn in an attempt to plan a way forward within the context of a contemporary South Africa, balancing the needs of a diverse student body and the necessity to motivate law students to apply critical thinking techniques.

\section{ACKNOWLEDGEMENT}

Thanks go to Dr Caroline Goodier for her assistance in designing and developing the LRWR legal writing programme. 